\title{
A screen for peptide agonists of the G-CSF receptor
}

\author{
Nadine Conzelmann and Armin Schneider
}

\begin{abstract}
Background: Granulocyte-colony stimulating factor (G-CSF) is one of the most important pharmacologically used proteins. Potential uses beyond the stimulation of neutrophilic granulocytes are the treatment of CNS disorders. Disadvantages of the G-CSF protein as a drug are its moderate plasma half-life time and considerable production costs. We therefore conducted a screen for peptide agonists derived from the sequence of human G-CSF.

Findings: Despite of the high sensitivity of our screening system we could not detect any positive hits in a single peptide approach. In a multiplex approach using a permutation of any combination of 10 different peptides we could also not detect a positive block.
\end{abstract}

Conclusions: We conclude that larger coherent parts of the protein or dimerising peptides may be needed to achieve activation of the receptor.

\section{Background}

Granulocyte-colony stimulating factor (G-CSF) is one the most widely employed protein drugs. It is mostly used for counteracting neutropenia in patients receiving chemotherapy [1], but also for stem cell harvesting [2,3], and as add-on to anti-infectious therapy. G-CSF is a glycoprotein that binds in 2:2 ligand: receptor stoichiometry to its cytokine like receptor (G-CSF-R) which recruits in turn Janus kinases (JAKs), a family of protein tyrosine kinases. These kinases phosphorylate the receptor and also themselves starting by that a multiple signalling cascade, which involves amongst others STAT1 and 3, PI3K/Akt and the Ras/Mek/Erk1/2 pathway [4-8].

Recently we and others have defined a novel spectrum of G-CSF activities in the central nervous system where it acts on neurons. For example, it was shown that GCSF can reduce the infarct size in animal stroke models [9-11] and that it has significant beneficial effects on the motor performance as well as on the overall survival in a mouse model for Amyotrophic lateral sclerosis (ALS) [12]. G-CSF is therefore clinically explored for several neurological diseases, such as stroke [13,14].

Disadvantages of the G-CSF protein for a potential lifetime continuous therapy as in the case of chronic neurodegenerative conditions are its limited plasma

* Correspondence: schneider@sygnis.de

SYGNIS Bioscience, Im Neuenheimer Feld 515, 69120 Heidelberg, Germany half-life time $(\sim 4 \mathrm{~h})$, the relatively high costs, and chronic effects on the hematopoietic system. Pegylated forms of G-CSF are available that have a much extended half-life, however, it is unclear at present if those modifications hinder passage of the blood-brain-barrier (BBB).

We therefore decided to conduct a screen searching for peptides derived from the human G-CSF peptide sequence with agonistic activity. Peptides would be considerably cheaper to produce, be potentially suitable for delivery methods other than subcutaneous injection, and might also show improved neuronal selectivity.

It was previously shown for a number of protein receptors that this is a feasible concept in principle. For example, peptides derived from the NCAM (neural cell adhesion molecule) sequence, a cell surface glycoprotein that belongs to the Ig superfamily, act agonistically on the fibroblast growth factor (FGF) receptor [15-17]. NCAM is involved in the formation of neuronal connections during development and modulates synaptic plasticity associated with regeneration and learning [18-20]. Several mimetic peptides have been derived from its protein structure, like $\mathrm{C} 3$ by combinatorial chemistry from the NCAM Ig1 module [21], the BCL motif from the second NCAM fibronectin type III module [22] and P2, a 12 amino acid sequence localized in the FG loop of the second Ig module of NCAM [23]. All these 
peptides are potent mimetics of NCAM and therefore attractive compounds in the development of therapies in neurodegenerative disorders.

Moreover, agonistic peptides have been found for the EPO receptor (EPO-R), functionally very close to the GCSF receptor (G-CSF-R), both derived from the EPO sequence [24] or fully novel $[25,26]$. Indeed, one of the agonistic peptides has entered clinical development [27]. This agonistic peptide for the EPO-R (EMP-1) was discovered by phage display and is a cyclic peptide of 20 residues, which has nothing in common with the original EPO protein structure. EMP-1 can compete with $\mathrm{EPO}$ at micromolar concentrations by binding as a dimer to the extracellular domain of the EPO-R and by activating the receptor by induced dimerization. This was also shown by the crystal structure of the complex of EMP-1 with recombinant soluble EPO-receptor. In two animal models for erythropoesis EMP-1 also exhibited activity $[26,28]$. In further development steps EMP1 has been chemically modified through covalent linkage of polyethylene glycol resulting in the EMP-1 related dipeptide Hematide ${ }^{\mathrm{TM}}$ [26]. Hematide ${ }^{\mathrm{TM}}$ obtained an increased half life and has been shown to be safe in healthy volunteers by increasing haemoglobin levels for one month [29]. A clinical trial phase III has just been completed in 2010.

In 1998 the nonpeptidyl small molecule SB 247464 was identified as a ligand of the murine G-CSF receptor in a high-throughput cell based screening approach by Tian and colleagues [30]. Like G-CSF, SB 247464 induced tyrosine phosphorylation of multiple signaling proteins, and stimulated primary murine bone marrow cells by oligomerizing the receptor chains. Nonetheless the synthetic compound showed lower potency compared to G-CSF and bound exclusively to the murine but not the human G-CSF-R [30]. Up to now no other agonistic small molecules or peptides for the human GCSF-R have been identified or described.

Thus we conducted a sensitive screen for peptide agonists derived from the sequence of human G-CSF employing the murine myeloblastic cell line NFS-60. This suspension cell line expands rapidly in culture and is dependent on G-CSF of either murine or human origin, or alternatively on M-CSF (Macrophage colony-stimulating factor) or IL-3 (Interleukin-3) [31]. Our assay read-out was viability of these cells in the absence of G-CSF.

\section{Methods}

\section{Peptide Library}

For the design of the peptide library the protein sequence of human G-CSF [NCBI: NP_000750] was used. The first 29 amino acids of the G-CSF protein (the signal sequence) were not considered for the library. For the remaining 178 amino acids of the GCSF sequence we designed an overlapping peptide library for G-CSF with the help of the PepScreen ${ }^{\circledR}$ Library Design Tool [32]. We chose an overlapping 20 mer peptide library with a shift of 2 amino acids per peptide, resulting in a total of 80 peptides. The peptide library was ordered in crude quality with a minimum content of $30 \%$ intact peptide that was analyzed by MS and HPLC by the provider (Genscript USA Inc., Piscataway, NJ, USA). Because of the on average high hydrophobicity of the peptides they were dissolved in DMSO at a concentration of $1 \mathrm{mM}$ and stored at $-80^{\circ} \mathrm{C}$.

\section{Cell line}

The murine myeloblastic cell line NFS-60 expands rapidly in culture and is dependent on G-CSF of either murine or human origin, or alternatively on M-CSF (Macrophage colony-stimulating factor) or IL-3 (Interleukin-3) [31]. The cell line was cultured as suspension culture in RPMI 1640 medium supplemented with 5.1 $\mathrm{ml} \mathrm{L}$-glutamine $(200 \mathrm{mM}), 10 \%$ fetal bovine serum, $1 \mathrm{x}$ $\mathrm{P} / \mathrm{S}, 10 \mu \mathrm{M} \beta$-Mercaptoethanol and $2 \mathrm{ng} / \mathrm{ml} \mathrm{G}$-CSF at $37^{\circ} \mathrm{C}$ and with a $\mathrm{CO}_{2}$ fraction of $5 \%$.

\section{Establishing viability curves for G-CSF dependency}

NFS-60 cells were washed twice with cell culture medium containing no G-CSF and were then plated at a total density of $1 \times 10^{4} /$ well in 96 -well plates. Subsequently human recombinant G-CSF (AX200, Dr. Reddy's Laboratories, Hyderabad, India; $300 \mu \mathrm{g} / \mathrm{ml}$ ) was added to the cells at increasing concentrations, and cells were incubated for $48 \mathrm{~h}$ at $37^{\circ} \mathrm{C}$. Viability of the cells was detected using the MultiTox-Fluor Multiplexicity Assay (Promega, Mannheim, Germany) as described by the provider. Fluorescence was measured using the plate reader FLUOstar (BMG Labtech, Offenburg, Germany) at $390 \mathrm{~nm} / 520 \mathrm{~nm}$.

\section{Screening of single peptides}

96-well plates were prepared with 8 peptides with 8 replicates/plate, 2 negative controls (G-CSF buffer (10 $\mathrm{mM}$ Acetic Acid, $250 \mathrm{mM}$ Sorbitol, 0.004\% Tween 80)) at 8 replicates/plate, and two positive controls, one at the lower end of sensitivity, and one at a $100 \%$ viability level (each at 8 replicates). In order to avoid evaporation of the edging wells and to have the same conditions for all probes the samples with their eight replicates were pipetted in a diagonal pattern on a 96-well plate automatically by the MultiProbeII EX from Packard [Additional file 1].

NFS-60 cells were washed twice with cell culture medium containing no G-CSF and were then plated in a 96well plate at a total cell number of $1 \times 10^{4} /$ well. The peptide plate was then transferred by the Liquidator ${ }^{96}$ 
(Steinbrenner Laborsysteme $\mathrm{GmbH}$ ) to this plate and incubated at $37^{\circ} \mathrm{C}$ for 48 hours. Final DMSO concentrations were $0.2 \%$ for the $1 \mu \mathrm{M}$ screen, and $2 \%$ for the 10 $\mu \mathrm{M}$ screen. For detection of viability the MultiTox-Fluor Multiplexicity Assay from Promega was used as described by the provider. The fluorescence of the plate was measured in a fluorescence reader (FLUOstar) at $390 \mathrm{~nm}$ and $520 \mathrm{~nm}$.

\section{Screening of multiple peptides}

Up to 20 peptides per well were tested in a multiplex approach. The 80 peptides of the library were arranged in eight groups per ten peptides. Permutations of all combinations of two peptide groups were tested.

\section{Statistical Analyses}

All results were evaluated in EXCEL. For analysis of the data a student's t-test against both negative controls was performed. A p-value $<0.05$ was considered significant.

\section{Results}

\section{Development of a screening assay based on G-CSF} dependency

We used the G-CSF-dependent cell line NFS-60 for screening a library of G-CSF-derived peptides. First we established a survival curve over a wide concentration range of G-CSF (Figure 1) with a resulting EC50 value about $0.8 \mathrm{pM}$ or $18 \mathrm{pg} / \mathrm{ml}$ G-CSF. For the subsequent peptide screen we chose two positive controls, one at $100 \%$ viability $(0.1 \mathrm{nM}$ or $2 \mathrm{ng} / \mathrm{ml} \mathrm{G}$-CSF), Figure 1 closed circle), and one at the lowest G-CSF concentration that still had a significant effect on viability $(0.1 \mathrm{pM}$ or $2.7 \mathrm{pg} / \mathrm{ml} \mathrm{G-CSF}$, Figure 1 dashed circle). These two concentrations first guarantee a constant sensitivity of

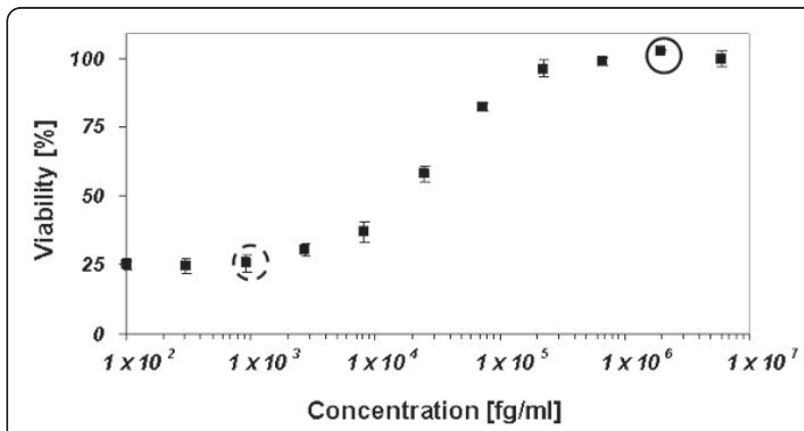

Figure 1 Titration curve of G-CSF on the G-CSF dependant cell line NFS-60. NFS-60 were incubated with increasing concentrations of G-CSF for $48 \mathrm{~h}$. The resulting viability curve was used to choose positive controls for the subsequent screen $(0.1 \mathrm{nM}$ and $0.1 \mathrm{pM} \mathrm{G}$ CSF). The concentration of $0.1 \mathrm{nM}$ (closed circle) corresponds to $100 \%$ viability of the cells. The concentration of $0.1 \mathrm{pM}$ (dashed circle) reflects the lowest significant increase in viability observed. the assay, and would allow estimating the relative potency of hits.

\section{Screening of single peptides}

We designed a 20-mer peptide library derived from the human G-CSF sequence with a sliding overlap of 2 amino acids. We first conducted a screen at a concentration of 1 $\mu \mathrm{M}$ per peptide, a $10^{4}$-fold higher molarity than the lower positive control. Results for the 80 peptides are given in Figure 2 with means of the two positive controls over all screened plates indicated as red lines in the diagram (dotted, lower positive control; dashed, upper positive control). Negative controls are shown as grey bars. The mean standard deviation over 8 replicates of the negative controls was $+/-6.37 \%$, of the screened peptides $+/-5.81 \%$. None of the 80 peptides screened showed a significant increase in viability compared to the negative controls.

We conducted a second screen at a concentration of $10 \mu \mathrm{M}$ per peptide. This resulted in an increase of the DMSO concentration to $2 \%$, the highest level tolerated by the NFS-60 cell line as established before (data not shown). While at a $2 \%$ DMSO concentration the upper positive control remained at $0.1 \mathrm{nM}$ as above, the lower positive control had to be elevated to $3.4 \mathrm{pM}$ to show clear increase in viability. These concentrations were chosen as lower and upper positive control in the screen. Results are shown in Figure 3. Because of the tenfold increased DMSO content the average viability of the negative controls was clearly decreased relative to the previous screen. Positive controls again showed a

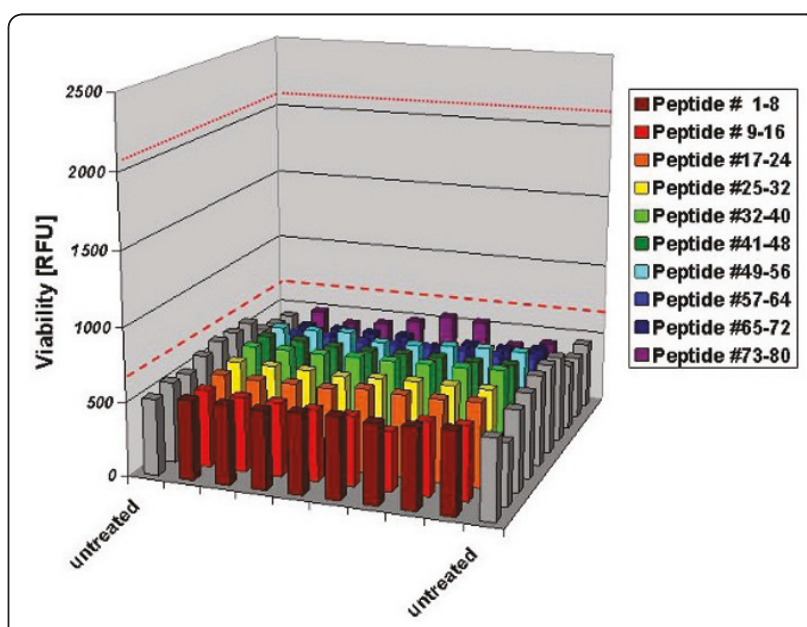

Figure 2 Results of the G-CSF peptide screening at $1 \mu \mathrm{M}$. Controls on each 96-well plate included two negative controls without G-CSF and two positive controls with a molarity of $0.1 \mathrm{nM}$ and $0.1 \mathrm{pM}$ G-CSF. The mean of the two positive controls are indicated as red lines (red dotted line $=$ first positive control, red dashed line $=$ second positive control). None of the 80 peptides screened showed a significant increase in viability compared to the negative controls. ( $n=8$ replicates each). 


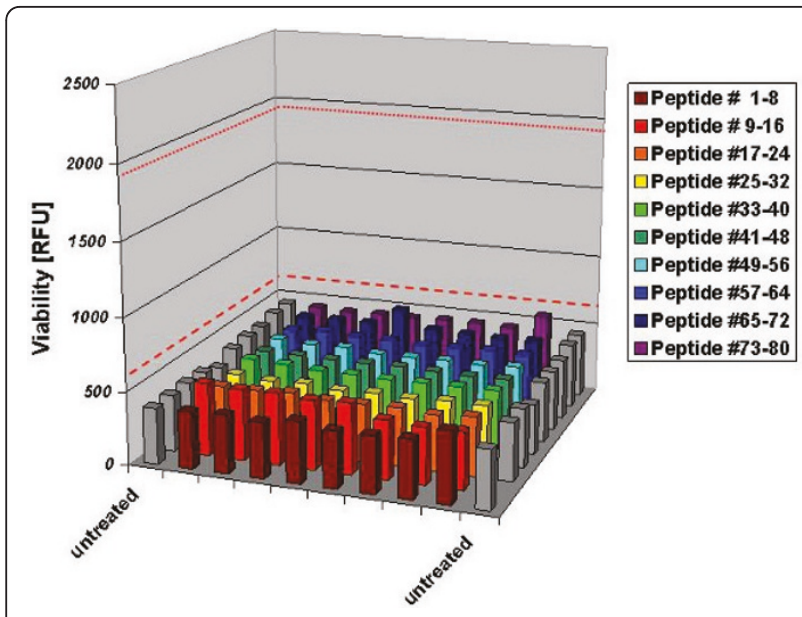

Figure 3 Results of the G-CSF peptide screening at $10 \mu \mathrm{M}$. Controls on each 96-well plate included two negative controls without G-CSF and two positive controls with a concentration of 0.1 $\mathrm{nM}$ and 3.4 pM G-CSF. Second positive control had to be adapted due to an increased DMSO concentration. The mean of the two positive controls over all plates are indicated as red lines (red dotted line $=$ first positive control, red dashed line $=$ second positive control). None of the 80 peptides showed a significantly increased viability compared to the negative controls. $(n=8$ replicates each).

significant increase in viability in all plates screened (mean values as red lines). None of the 80 peptides showed any significant increase in viability.

\section{Screening of peptides in a multiplex approach}

As both screening approaches of single peptides with molarities of $1 \mu \mathrm{M}$ and $10 \mu \mathrm{M}$ were unsuccessful, we finally tried a multiplex approach, based on possibly necessary cooperative effects of different protein epitopes in order to activate the G-CSF receptor. As the cell line NFS60 showed high sensitivity towards higher DMSO concentrations the maximum number of peptides to be tested per well were 20 at a total molarity of $10 \mu \mathrm{M}$ (single concentration $0.5 \mu \mathrm{M})$. This resulted in a DMSO content of $2 \%$.

Figure 4 shows the results of this multiplex screening approach. Negative controls are represented as grey bars, whereas the positive controls are displayed in red lines. Negative controls displayed low viability comparable to the $10 \mu \mathrm{M}$ single peptide screen. Although every possible combination of any two peptides derived from the G-CSF sequence was tested, the screen did also not yield any significant hits. Some of the peptide combinations appeared to have a small increase in viability but these elevations were never significant and never in the range of the lower positive control.

\section{Discussion}

In the present study we have utilized the G-CSF dependence of the cell line NFS-60 to screen for agonistic

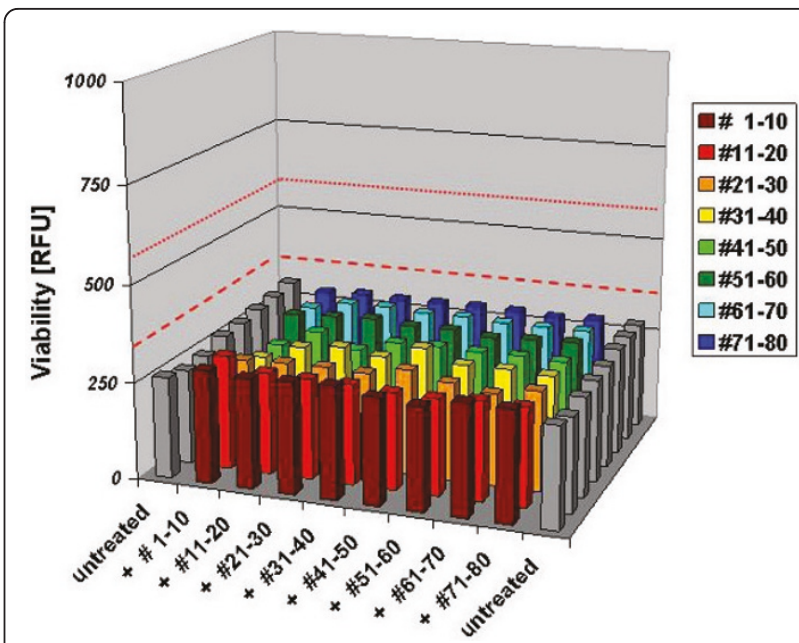

Figure 4 Results of the multiplex peptide screening approach. NFS-60 were incubated with four controls and eight peptide blocks. Controls included two negative controls without G-CSF and two positive controls with a molarity of $0.1 \mathrm{nM}$ and $3.4 \mathrm{pM} \mathrm{G-CSF}$ (adapted control due to increased DMSO concentration). One peptide block consisted of ten peptides in increasing order and was combined with the remaining seven peptide blocks. None of the combinations showed an increase in viability at a total molarity of $10 \mu \mathrm{M}$ compared to the negative controls. ( $\mathrm{n}=8$ replicates each).

peptides derived from the G-CSF human sequence. Although the screening system was highly sensitive and would have allowed the detection of an agonistic peptide at least $3.4 \times 10^{7}$-fold less potent than the parent protein, we could not detect any positive hits. Also in a multiplex approach using a permutation of any combination of 10 different peptides we could not detect a positive block. A post-hoc power analysis of our screen revealed that it should have been possible to detect an increase in viability down to $10 \%$ with a power of $80 \%$.

Reasons for this failure may either be technical problems, or principal in nature. We believe that the latter is true. The coverage of the G-CSF sequence was certainly dense with a frame shifted by 2 amino acids over the entire sequence. The purity of the synthesized peptides was reasonable with a minimum content of pure and intact peptide of $30 \%$, and the peptides were all fully dissolved at the assayed concentrations.

It is possible that the length of the peptides was not sufficient. However, other agonistic peptides described for the EPO (Erythropoietin) receptor or NCAM (neural cell adhesion molecule) have 20 or less amino acids. Screening much longer peptides would also make less sense in view of their pharmaceutical advantage over the full-length protein.

An interesting point is the potential need for dimerising peptides. G-CSF itself dimerizes when binding to its receptor, and induces receptor dimerization [4-6]. Indeed, an engineered G-CSF dimer (F-627) appears 
more potent in vivo than the monomer form [33]. It has also been speculated that the nonpeptidyl small molecule SB 247464 acts because of its twofold rotational symmetry as a dimerization inducer of the G-CSF receptor [30]. It may therefore be advantageous in future approaches to utilize dimerizing peptides for such a screen.

\section{Additional material}

\section{Additional file 1: Schematic design of the screening plates}

Description: 96-well plates were filled in a diagonal way to avoid evaporation effects and to get equal conditions for every sample. (A and B) Exemplary design of plates for $1 \mu \mathrm{M}$ and $10 \mu \mathrm{M}$ screening. Plates contained two negative controls, two positive controls and eight peptides with arising numbering. Second positive control had to be adapted due to increased DMSO content in the $10 \mu \mathrm{M}$ screening. (C) Exemplary graphic of plates for the multiplex screening. Layout of controls was analogue to the $10 \mu \mathrm{M}$ screening.

\section{List of abbrevations}

(G-CSF): Granulocyte-colony stimulating factor; (G-CSF-R): Granulocyte-colony stimulating factor receptor; (JAK): Janus kinase; (ALS): Amyotrophic lateral sclerosis; (BBB): blood-brain-barrier; (NCAM): neural cell adhesion molecule; (FGF): fibroblast growth factor, (EPO-R): Erythropoietin receptor; (M-CSF): Macrophage colony-stimulating factor; (IL-3): Interleukin-3.

\section{Acknowledgements}

We thank Frank Herzog, Uli Bolz, Simone Hoppe, and Gisela Eisenhardt for excellent technical help. This work was supported by a grant from the BioProfile für die Region Braunschweig, Göttingen, Hannover (Forschungsvorhaben 0315180C).

\section{Authors' contributions}

NC established, designed, and carried out the screening assay and analysis, and wrote the manuscript. AS conceived the study, contributed to analysis of the data, and wrote the manuscript. Both authors read and approved the final manuscript.

\section{Competing interests}

The authors are employees of SYGNIS Bioscience. This does not interfere with any aspects of this study.

Received: 16 March 2011 Accepted: 15 June 2011 Published: 15 June 2011

\section{References}

1. Neidhart J, et al: Granulocyte colony-stimulating factor stimulates recovery of granulocytes in patients receiving dose-intensive chemotherapy without bone marrow transplantation. J Clin Oncol 1989, 7(11):1685-92.

2. Johnsen $\mathrm{HE}$, et al: Increased yield of myeloid progenitor cells in bone marrow harvested for autologous transplantation by pretreatment with recombinant human granulocyte-colony stimulating factor. Bone Marrow Transplant 1992, 10(3):229-34.

3. Sheridan WP, et al: Granulocyte colony-stimulating factor and neutrophil recovery after high-dose chemotherapy and autologous bone marrow transplantation. Lancet 1989, 2(8668):891-5.

4. Tian SS, et al: Rapid activation of the STAT3 transcription factor by granulocyte colony-stimulating factor. Blood 1994, 84(6):1760-4.

5. Nicholson SE, et al: Tyrosine kinase JAK1 is associated with the granulocyte-colony-stimulating factor receptor and both become tyrosine-phosphorylated after receptor activation. Proc Natl Acad Sci USA 1994, 91(8):2985-8.
6. Ihle JN, et al: Signaling through the hematopoietic cytokine receptors. Annu Rev Immunol 1995, 13:369-98.

7. Tamada $T$, et al: Homodimeric cross-over structure of the human granulocyte colony-stimulating factor (GCSF) receptor signaling complex. Proc Natl Acad Sci USA 2006, 103(9):3135-40.

8. Zhu QS, et al: G-CSF-induced tyrosine phosphorylation of Gab2 is Lyn kinase dependent and associated with enhanced Akt and differentiative, not proliferative, responses. Blood 2004, 103(9):3305-12.

9. Schabitz WR, et al: Neuroprotective effect of granulocyte colonystimulating factor after focal cerebral ischemia. Stroke 2003, 34(3):745-51.

10. Schneider A, Kuhn HG, Schabitz WR: A role for G-CSF (granulocyte-colony stimulating factor) in the central nervous system. Cell Cycle 2005, 4(12):1753-7.

11. Schneider A, et al: The hematopoietic factor G-CSF is a neuronal ligand that counteracts programmed cell death and drives neurogenesis. $J$ Clin Invest 2005, 115(8):2083-98.

12. Pitzer $\mathrm{C}$, et al: Granulocyte-colony stimulating factor improves outcome in a mouse model of amyotrophic lateral sclerosis. Brain 2008, 131(Pt 12):3335-47

13. Tarella C, et al: Consistent bone marrow-derived cell mobilization following repeated short courses of granulocyte-colony-stimulating factor in patients with amyotrophic lateral sclerosis: results from a multicenter prospective trial. Cytotherapy 2010, 12(1):50-9.

14. Schabitz WR, et al: AXIS: a trial of intravenous granulocyte colonystimulating factor in acute ischemic stroke. Stroke 2010, 41(11):2545-51.

15. Hansen SM, et al: Synthetic NCAM-derived ligands of the fibroblast growth factor receptor. Adv Exp Med Biol 2010, 663:355-72.

16. Manfe $V$, et al: Peptides derived from specific interaction sites of the fibroblast growth factor 2-FGF receptor complexes induce receptor activation and signaling. J Neurochem 2010, 114(1):74-86.

17. Kiselyov W, et al: Structural basis for a direct interaction between FGFR1 and NCAM and evidence for a regulatory role of ATP. Structure 2003, 11(6):691-701.

18. Tomasiewicz $\mathrm{H}$, et al: Genetic deletion of a neural cell adhesion molecule variant (N-CAM-180) produces distinct defects in the central nervous system. Neuron 1993, 11(6):1163-74.

19. Cremer $\mathrm{H}$, et al: Inactivation of the $\mathrm{N}-\mathrm{CAM}$ gene in mice results in size reduction of the olfactory bulb and deficits in spatial learning. Nature 1994, 367(6462):455-9.

20. Ronn LC, Hartz BP, Bock E: The neural cell adhesion molecule (NCAM) in development and plasticity of the nervous system. Exp Gerontol 1998, 33(7-8):853-64.

21. Ronn LC, et al: Identification of a neuritogenic ligand of the neural cell adhesion molecule using a combinatorial library of synthetic peptides. Nat Biotechnol 1999, 17(10):1000-5.

22. Jacobsen J, et al: A peptide motif from the second fibronectin module of the neural cell adhesion molecule, NCAM, NLIKQDDGGSPIRHY, is a binding site for the FGF receptor. Neurochem Res 2008, 33(12):2532-9.

23. Soroka $V$, et al: Induction of neuronal differentiation by a peptide corresponding to the homophilic binding site of the second Ig module of the neural cell adhesion molecule. J Biol Chem 2002, 277(27):24676-83.

24. Pankratova $S$, et al: Neuroprotective properties of a novel, nonhaematopoietic agonist of the erythropoietin receptor. Brain 2010.

25. Johnson $\mathrm{DL}$, et al: Identification of a 13 amino acid peptide mimetic of erythropoietin and description of amino acids critical for the mimetic activity of EMP1. Biochemistry 1998, 37(11):3699-710.

26. Livnah $\mathrm{O}$, et al: Functional mimicry of a protein hormone by a peptide agonist: the EPO receptor complex at 2.8 A. Science 1996, 273(5274):464-71.

27. Macdougall IC, et al: A peptide-based erythropoietin-receptor agonist for pure red-cell aplasia. N Engl J Med 2009, 361(19):1848-55.

28. Wrighton NC, et al: Small peptides as potent mimetics of the protein hormone erythropoietin. Science 1996, 273(5274):458-64.

29. Stead RB, et al: Evaluation of the safety and pharmacodynamics of Hematide, a novel erythropoietic agent, in a phase 1, double-blind, placebo-controlled, dose-escalation study in healthy volunteers. Blood 2006, 108(6):1830-4.

30. Tian SS, et al: A small, nonpeptidyl mimic of granulocyte-colonystimulating factor [see comments]. Science 1998, 281(5374):257-9. 
31. Nakoinz I, et al: Differentiation of the IL-3-dependent NFS-60 cell line and adaption to growth in macrophage colony-stimulating factor. I Immunol 1990, 145(3):860-4

32. PepScreen ${ }^{\mathbb{B}}$ Library Design Tool. [http://www.sigmaaldrich.com/lifescience/custom-oligos/custom-peptides/learning-center/pepscreencalculator.html], Available from.

33. Zheng TH, et al: F-627, a G-CSF Dimer, Stimulated a More Rapid Neutrophil Recovery In Cyclophosphamide-Treated Monkeys Compared to Monomer Rhg-CSFs. ASH Annual Meeting and Exposition Orange County Convention Centre, Orlando FL; 2010, Ph.D.1*.

doi:10.1186/1756-0500-4-194

Cite this article as: Conzelmann and Schneider: A screen for peptide agonists of the G-CSF receptor. BMC Research Notes 2011 4:194.

Submit your next manuscript to BioMed Central and take full advantage of:

- Convenient online submission

- Thorough peer review

- No space constraints or color figure charges

- Immediate publication on acceptance

- Inclusion in PubMed, CAS, Scopus and Google Scholar

- Research which is freely available for redistribution

Submit your manuscript at www.biomedcentral.com/submit 